\title{
Blockade of Neuronal Nitric Oxide Synthase Protects against Excitotoxicity in vivo
}

\author{
Jörg B. Schulz, ${ }^{1}$ Russell T. Matthews, ${ }^{1}$ Bruce G. Jenkins, ${ }^{2}$ Robert J. Ferrante, ${ }^{3}$ Donald Siwek, ${ }^{3}$ D. Ross \\ Henshaw, ${ }^{1}$ P. Ben Cipolloni, ${ }^{3}$ Patrizia Mecocci, ${ }^{1}$ Neil W. Kowall, ${ }^{3}$ Bruce R. Rosen, ${ }^{2}$ and M. Flint Beal ${ }^{1}$ \\ 'Neurochemistry Laboratory, Neurology Service, and ${ }^{2} \mathrm{MGH}-\mathrm{NMR}$ Center, Department of Radiology, Massachusetts \\ General Hospital and Harvard Medical School, Boston, Massachusetts 02114 and ${ }^{3}$ Geriatric Research Education \\ and Clinical Center, Bedford VA Medical Center, Department of Neurology and Pathology, Boston University School \\ of Medicine, Boston, Massachusetts 02115
}

Nitric oxide may be a key mediator of excitotoxic neuronal injury in the central nervous system. We examined the effects of the neuronal nitric oxide synthase inhibitor 7-nitroindazole (7-NI) on excitotoxic striatal lesions. 7-NI significantly attenuated lesions produced by intrastriatal injections of NMDA, but not kainic acid or $\alpha$-amino-3-hydroxy-5-methyl-4-isoxazolepropionic acid (AMPA). 7-NI attenuated secondary striatal excitotoxic lesions produced by the succinate dehydrogenase inhibltor malonate, and the protection was reversed by L-arginine but not by D-arginine. 7-NI produced nearly complete protection against striatal lesions produced by systemic administration of 3-nitropropionic acid (3-NP), another succinate dehydrogenase inhibitor. 7-NI protected against malonate induced decreases in ATP, and increases in lactate, as assessed by 'H magnetic resonance spectroscopy. 7-NI had no effects on spontaneous electrophysiologic activity in the striatum in vivo, suggesting that its effects were not mediated by an interaction with excitatory amino acid receptors. 7-NI attenuated increases in hydroxyl radical, 8-hydroxy-2-deoxyguanosine and 3-nitrotyrosine generation in vivo, which may be a consequence of peroxynitrite formation. The present results implicate neuronal nitric oxide generation in the pathogenesis of both direct and secondary excitotoxic neuronal injury in vivo. As such they suggest that neuronal nitric oxide synthase inhibitors may be useful in the treatment of neurologic diseases in which excitotoxic mechanisms play a role.

[Key words: nitric oxide synthase, excitotoxicity, 7-nitroindazole, nitrotyrosine, free radicals, Huntington's disease]

The role of nitric oxide (NO) in neuronal injury is an area of intense investigation. The initial studies of Dawson and colleagues implicated $\mathrm{NO}^{-}$in excitotoxic cell death following the activation of NMDA receptors (Dawson et al., 1991). Subse-

\footnotetext{
Received Apr. 14, 1995; revised Aug. 25, 1995; accepted Aug. 31, 1995.

Sharon Melanson is thanked for secretarial assistance. JBS is supported by a Fellowship of the Deutsche Forschungsemeinschaft (Schu 932/1-2). This work was supported by NIH Grants NS16367, NS10828, and NS31579. Dr. Bruce Ames supplied a monoclonal antibody to 8-hydroxy-2-deoxyguanosine and Dr. Joseph Beckman a polyclonal antibody to 3-nitrotyrosine.

Correspondence should be addressed to M. Flint Bcal, M.D., Ncurology Scrvice, Warren 408, Massachusetts General Hospital, Boston, MA 02114.

Copyright $\odot 1995$ Society for Neuroscience $0270-6474 / 95 / 158419-11 \$ 05.00 / 0$
}

quently inhibition of NOS was reported to show protection in a model of cerebral ischemia in vivo (Nowicki et al., 1991). These findings; however, have been controversial since some authors found no protection. The ahsence of consensus may be due to the prior lack of $\mathrm{NO}^{*}$ synthase inhibitors with specificity for various isoforms of the enzyme. Strong evidence for a role of neuronal nitric oxide synthase (NOS) in focal ischemia has come from studies in mice with a knockout of the neuronal isoform of NOS. These mice show a significant attenuation in the size of focal ischemic lesions (Huang et al., 1994).

Improved inhibitors of NOS have recently been described. One of these is 7-nitroindazole (7-NI) which is a relatively specific inhibitor of the neuronal isoform of NOS in vivo. Although in vitro studies suggest that it inhibits both endothelial and neuronal NOS, in vivo studies showed no effects on blood pressure, on endothelium-dependent blood vessel relaxation and on $\mathrm{ACh}$ induced blood vessel relaxation (Babbedge et al., 1993; Moore et al., 1993; Wolff and Gribin, 1994; Yoshida et al., 1994). 7-NI is efficacious against focal ischemic lesions in vivo (Yoshida et al., 1994), and we found that it blocks MPTP neurotoxicity in vivo (Schulz et al., 1995b).

In the present study we examined the hypothesis that neuronal NOS plays a role in excitotoxicity in vivo. We examined whether 7-NI can block striatal lesions produced by NMDA, kainic acid or AMPA. We also investigated its effects on secondary excitotoxic lesions produced by the reversible succinate dehydrogenase inhibitor malonate, and the irreversible succinate dehydrogenase inhibitor 3-nitropropionic acid. To evaluate the mechanism of neuroprotection we investigated the effects of 7-NI on spontaneous striatal electrophysiologic activity, and ATP depletions produced by malonate. We also investigated its effects on NMDA and 3-NP induced hydroxyl $(\mathrm{OH})$ radical generation, increases in 8-hydroxy-2-deoxyguanosine a marker of oxidative damage to DN $\Lambda$, and increases in 3-nitrotyrosine, which may be a consequence of peroxynitrite formation (Beckman et al., 1990, 1992; Crow et al., 1994).

\section{Materials and Methods}

Chemicals. Malonate, NMDA, kainic acid (KA), L-arginine, D-arginine, nitroblue tetrazolium, and peanut oil were obtained from Sigma (St. Louis, MO), $\alpha$-amino-3-hydroxy-5-methylisoxazole-4-proprionic acid (AMPA) from Research Biochemicals (Natick, MA), 3-nitropropionic acid (3-NP) from Aldrich (Milwaukee, WI), and 7-NI from Cookson Chemical Ltd. (Southampton, UK).

Stereotaxic lesion technique. Male Sprague-Dawley rats (Charles River, Cambridge, MA) weighing 300-325 gm were anesthetized with 
pentobarbital ( $50 \mathrm{mg} / \mathrm{kg}$ i.p.) and positioned in a David Kopf stereotaxic instrument with the incisor bar set at $3.3 \mathrm{~mm}$ below the interaural line Malonate, NMDA, KA, and AMPA were dissolved in $0.1 \mathrm{M}$ phosphatebuffered saline ( $\mathrm{pH} 7.4)$. Intrastriatal injections were made with a 10 $\mu l$ Hamilton syringe fitted with a 26 gauge blunt-tipped needle into the left striatum at the coordinates $0.5 \mathrm{~mm}$ anterior bregma, $2.6 \mathrm{~mm}$ lateral to the midline, and $5 \mathrm{~mm}$ ventral to the dura. Injection volumes were $1 \mu \mathrm{l}(5 \mathrm{nmol} \mathrm{KA}, 200 \mathrm{nmol} \mathrm{NMDA}$, and $30 \mathrm{nmol}$ AMPA), and $1.5 \mu \mathrm{l}$ ( $3 \mu \mathrm{mol}$ malonate). All injections were made over $1 \mathrm{~min}$ and the needle was left in place for an additional $1 \mathrm{~min}$ before being slowly withdrawn 7-NI was dissolved and sonicated in peanut oil at a concentration of 10 $\mathrm{mg} / \mathrm{ml}$. Animals were treated with peanut oil (vehicle) or $50 \mathrm{mg} / \mathrm{kg}$ of 7-NI were administered i.p. $0.5 \mathrm{hr}$ before striatal injections of malonate, NMDA, KA, and AMPA. The ability of $300 \mathrm{mg} / \mathrm{kg}$ i.p. of L-arginine and $\mathrm{D}$-arginine coinjected with 7-NI, 0.5 hr before striatal injections to block the neuroprotective effects of 7-NI on striatal malonate lesions was also examined. Since this paradigm did not show any protective effects for NMDA, KA, and AMPA injections as compared to controls, in a second experiment two doses of $50 \mathrm{mg} / \mathrm{kg}$ of 7-NI were administered i.p. at $4 \mathrm{hr}$ and $0.5 \mathrm{hr}$ before striatal injections of NMDA, KA and AMPA. An identical protocol was used to assess the effects of 7-NI on neurochemical measurements following intrastriatal injections of saline, NMDA or KA. Initial results showed that 7-NI significantly decreased body temperature in rats under pentobarbital anesthesia measured $1 \mathrm{hr}$ after administration of $50 \mathrm{mg} / \mathrm{kg} 7-\mathrm{NI}$ i.p. $\left(35.9 \pm 0.2^{\circ} \mathrm{C}\right.$ vs $36.5 \pm 0.1^{\circ} \mathrm{C}, n=10, p<0.02$ ). Since hypothermia may produce neuroprotection, the body temperature was maintained at $37.5^{\circ} \mathrm{C}$ in an incubator as long as the animals were anesthetized. Temperature was monitored using a rectal thermister. Nine to 10 animals were used per group in each experiment.

Quantification of lesion volume. One week after the striatal injections, animals were sacrificed by decapitation and the brains were rapidly removed, placed in cold saline for $10 \mathrm{~min}$, and sectioned coronally into slices at $2 \mathrm{~mm}$ intervals. Slices were stained in 2\% 2,3,5-triphenyltetrazolium chloride monohydrate (TTC, Sigma, St. Louis, MO) solution at room temperature in the dark for $30 \mathrm{~min}$ followed by fixation in phosphate-buffered 4\% paraformaldehyde (Bedcrson ct al., 1986). The lcsioned area (noted by pale staining) was measured on the posterior surface of each section using an Apple Macintosh based image analysis system [Sony color video camera; software: COLORSNAP (Computer Friends Inc., Portland, OR) and IPLAB SPECTRUM (Signal Analytics, Vienna, VA)]. The lesions were evaluated by an experienced histologist blinded to the experimental conditions. We previously verified the reliability of the TTC measurements in animals injected with malonate on adjacent sections stained with either TTC or Nissl stain (Schulz et al., 1995a).

Systemic 3-NP treatment. 3-NP was diluted in water and adjusted to $\mathrm{pH} 7.4$ with $\mathrm{NaOH}$ and administered at a dose of $10 \mathrm{mg} / \mathrm{kg}$ i.p. every $12 \mathrm{hr}$. With this dosing regimen the animals become acutely ill after 4 $5 \mathrm{~d}$ and show large striatal lesions (Beal et al., 1993b). At the same time points $25 \mathrm{~m} \mathrm{~g} / \mathrm{kg}$ of 7-NI dissolved in peanut oil at a concentration of $10 \mathrm{mg} / \mathrm{ml}$ or vehicle alone (peanut oil) was administered s.c. Since there was variability in the times at which animals became ill, they were clinically examined $3 \mathrm{hr}$ after the injections and one animal of each group was sacrificed when an animal was acutely ill, regardless of whether it was a vehicle treated control or a 7-NI treated animal. In an initial experiment 12 animals per group were studied. In this experiment following sacrifice striatal lesion size was assessed by TTC staining.

In a second experiment five animals per group were studied with the same treatment paradigm for histology, and five animals received saline every $12 \mathrm{hr}$ for $4-5 \mathrm{~d}$. Three animals were treated with 7-NI alone every $12 \mathrm{hr}$ for $5 \mathrm{~d}$ as an additional control. A third group of five animals was treated with more prolonged administration of 3-NP and 7-NI: these animals were treated with 3-NP and 7-NI identically to animals of the other 7-NI treated group, but were not sacrificed when vehicle treated animals became ill but only later, when they showed symptoms. In this experiment animals were deeply anesthetized and transcardially perfused with ice cold saline, followed by phosphate buffered $4 \%$ paraformaldehyde (Beal et al., 1991). Brains were sectioned at $50 \mu \mathrm{m}$ intervals on a freezing microtome.

Enzyme histochemistry. Free floating sections were stained, using a modification of the direct method of Vincent and Johansson (1983) for demonstrating nicotinamide adenine dinucleotide phosphate dehydrogenase (NADPH-d). Tissue sections were incubated at $37^{\circ} \mathrm{C}$ and inter- mittently monitored for intensity for $1-3 \mathrm{hr}$ in a solution of $10 \mathrm{ml} 0.1$ $\mathrm{M}$ Tris $\mathrm{HCl}$ buffer ( $\mathrm{pH} 7.4$ ) containing $4 \mathrm{mg}$ NADPH and $10 \mathrm{mg}$ nitroblue tetrazolium salt (NBT). Increased intensity of reaction product was achieved by the addition of $0.8 \%$ Triton. Sections were doublelabeled, using a combined technique for NADPH-d enzyme histochemistry and Nissl staining. Heat treated tissue sections at $60^{\circ} \mathrm{C}$ for $2 \mathrm{hr}$ or incubating sections with NBT alone served as controls for specificity of enzyme activity.

Immunocytochemistry. Immunocytochemistry was performed on 50 $\mu \mathrm{m}$ thick tissue sections, using a conjugated second antibody method. The antisera used include those against 3-nitrotyrosine (monoclonal clone $1 \Lambda 6$ ), courtesy of Dr. Joseph Beckman, used at a dilution of 1:100 for free floating sections (Beckman et al., 1994); and 8-hydroxy-2-deoxyguanosine, courtesy of Dr. Bruce Ames, used at a dilution of 1:750 (Park et al., 1992). Preabsorption of antibodies with 3-nitrotyrosine and 8-hydroxy-2-deoxyguanosine respectively abolished staining. The procedure was as follows: the tissue sections were preincubated in absolute methanol $0.3 \%$ hydrogen peroxide solution for $30 \mathrm{~min}$, washed ( $3 X)$ in phosphate-buffered saline (PBS) (pH 7.4) 10 min each, placed in $10 \%$ normal goat serum (GIBCO Labs) for $1 \mathrm{hr}$, incubated free floating in primary antiserum at room temperature for $12-18 \mathrm{hr}$ (all dilutions of primary antisera above included $0.3 \%$ Triton X-100 and $10 \%$ normal goat serum), washed ( $3 \times$ ) in PBS for $10 \mathrm{~min}$ each, placed in periodateconjugated goat anti-rabbit IgG (1:300 in PBS) (Boehringer-Mannheim), washed $(3 X)$ in PBS 10 min each, and reacted with $3,3^{\prime}$ diaminobenzidine $\mathrm{HCl}(1 \mathrm{mg} / \mathrm{ml})$ in Tris $\mathrm{HCl}$ buffer with $0.005 \%$ hydrogen peroxide.

Blood pressure and heart rate measurements. Male Sprague-Dawley rats weighing 300-325 gm were anesthetized with pentobarbital and 22 gauge angiocatheters (Becton Dickinson, Sandy, UT) were placed in the femoral artery for arterial blood pressure measurements (ETH-400 transducer-amplifier, AD Instruments, Milford, MA). After recording baseline measurments $50 \mathrm{mg} / \mathrm{kg}$ of 7-NI in peanut oil was injected i.p. at time 0 and blood pressure and heart rate were recorded for $180 \mathrm{~min}$.

Salicylate assay, 3-nitrotyrosine, and 8-hydroxy-2-deoxyguanosine measurements. The salicylate hydroxyl trapping method (Floyd et al., 1984; Hall ct al., 1993) was uscd for mcasuring ${ }^{\circ} \mathrm{OH}$ radicals in striatal tissue following intrastriatal injection of NMDA and KA and i.p. administration of 3-NP. Male Sprague-Dawley rats weighing $300 \mathrm{gm}(n$ $=8$ per group) received intrastriatal injections of saline, NMDA, or $\mathrm{KA}$ as described above. Animals were treated with 7-NI $(50 \mathrm{mg} / \mathrm{kg})$ i.p. at $0.5 \mathrm{hr}$ before and at the time of striatal injections. Salicylate $(150$ $\mathrm{mg} / \mathrm{kg}$ i.p.) was administered at the time of the striatal injections.

In the 3-NP experiments rats weighing $125-150 \mathrm{gm}(n=10 \mathrm{per}$ group) were injected i.p. every $12 \mathrm{hr}$ for three doses with either (1) saline, (2) $20 \mathrm{mg} / \mathrm{kg}$ of $3-\mathrm{NP}$ and peanut oil vehicle, or (3) $20 \mathrm{mg} / \mathrm{kg}$ of $3-\mathrm{NP}$ and $25 \mathrm{mg} / \mathrm{kg}$ of $7-\mathrm{NI}$ dissolved in peanut oil. At $1.5 \mathrm{hr}$ after the last injection of 3-NP or saline, salicylate $(150 \mathrm{mg} / \mathrm{kg})$ was administered intraperitoneally. Sixty minutes later the animals were sacrificed and the right and left striata were rapidly dissected from a $2 \mathrm{~mm}$ thick slice on a chilled glass plate, and placed in $0.5 \mathrm{ml}$ chilled $0.1 \mathrm{M}$ perchloric acid. The samples were sonicated, rapidly frozen, thawed and centrifuged twice. Aliquots of the supernatant were stored at $-70^{\circ} \mathrm{C}$ until the time of assay.

Salicylate and its metabolites 2,3 and 2,5 dihydroxybenzoic acid (DHBA) were quantified by HPLC with 16 -electrode electrochemical detection (Beal et al., 1990). Salicylate, 2,3 and 2,5 DHBA, tyrosine and 3-nitrotyrosine were measured electrochemically by oxidation at $840,240,120,600$, and $840 \mathrm{mV}$, respectively, with retention times of $20.5,9.4,6.3,10.5$, and $18.2 \mathrm{~min}$, respectively. 3-Nitrotyrosine measurements were validated by changing chromatographic conditions, overspiking samples with authentic standards, demonstrating the correct electrochemical signature across 2 electrodes and by treating both samples and standards with $1 \mathrm{~m}$ sodium hydrosulfite which converts 3-nitrotyrosine to aminotyrosine eliminating the peak at $840 \mathrm{mV}$. The data were expressed as the ratio of 2,3 and 2,5 DHBA to salicylate and 3-nitrotyrosine to tyrosine to normalize the DHBA and 3-nitrotyrosine concentrations for differing brain concentrations of salicylate and tyrosine, which could be a consequence of impairment of the blood-brain harrier (salicylate) or neuronal loss during treatment (tyrosine). Eight saline treated and eight $3-\mathrm{NP}(20 \mathrm{mg} / \mathrm{kg})$ treated $250 \mathrm{gm}$ male SpragueDawley rats were sacrificed at $3 \mathrm{hr}$ and whole brain DNA was extracted and 8-hydroxy-2-deoxyguanosine was measured as previously described (Mecocci et al., 1993).

ATP measurements. The effects of 7-NI on malonate induced de- 
creases in striatal ATP concentrations were examined. $50 \mathrm{mg} / \mathrm{kg}$ of $7-\mathrm{NI}$ dissolved in peanut oil or peanut oil vehicle were administered i.p. 0.5 $\mathrm{hr}$ before intrastriatal injection of $3 \mu \mathrm{mol}$ malonate. At $3 \mathrm{hr}$ rats were deeply anesthetized and the skull surface was exposed. After decapitation the heads were rapidly frozen in liquid nitrogen and subsequently stored at $-70^{\circ} \mathrm{C}$. The striata were dissected from a $2 \mathrm{~mm}$ slice frontal to and adjacent to the anterior commissure on a freezing cold plate. The corpus callosum, the septal complex, and the anterior commissure were used as dorsal and lateral, medial, and ventral boundaries. ATP was measured by the luciferin-luciferase assay (Lust et al., 1981). Proteins were measured on the pellets using a fluorimetric assay. Eight animals per group were examined.

Localized lactate measurements by 'H magnetic resonance spectroscopy. The effects of intrastriatal injections of $3 \mu \mathrm{mol}$ malonate on lactate production and the influence of pretreatment with 7-NI on lactate production were assessed in vivo using magnetic resonance imaging (Brouillet et al., 1993b). Male Sprague--Dawley rats weighing 275-325 $\mathrm{gm}$ received either i.p. injections of peanut oil (vehicle) or $50 \mathrm{mg} / \mathrm{kg}$ 7-NI ( $n=5-6$ per group). One h later striatal injections of malonate were made as described above using halothanc ancsthesia. Rats werc imaged under halothane $/ \mathrm{N}_{2} \mathrm{O} / \mathrm{O}_{2}$ anesthesia on a 4.7 Tesla GE Omega CSI Imager using a $30 \mathrm{~mm}$ bird cage coil at $1.0-2.5 \mathrm{hr}$ after striatal malonate injections. Animals were maintained at normal body temperature by use of a temperature regulated circulating water blanket placed on the body of the animal. Lesion volumes were measured using a $\mathrm{T}_{2}$ weighted sequence (TR/TE $3200 / 80 \mathrm{msec}$ ) with slice thickness of 2.5 $\mathrm{mm}$, and a field of view of $40 \mathrm{~mm}$. Lesion volumes were measured using a criterion for abnormal tissue of being greater than 2 SDs above the mean signal intensity in the contralateral unaffected striatum. Lactate was measured using single phase encoding two-dimensional $(y, \omega)$ water supressed chemical shift imaging sequence with an inversion pulse for lipid supression described earlier (Jenkins et al., 1991; Henshaw et al., 1994). Parameters were TR/TE $/ \mathrm{TI}=2200 / 272 / 208 \mathrm{msec}$, with a field of view of $35 \mathrm{~mm}, 16$ phase encode steps and a slice thickness of $8 \mathrm{~mm}$. Lactate concentrations were measured in the lesioned striatum by averaging spectra through the striatum. The lactate signal was integrated using the NMR 2 package (New Method Research Inc., Syracuse, NY) and then normalized to the N-acetylaspartate (NAA) signal intensity in the contralateral striatum, which was assumed to be $7 \mathrm{~mm}$ in concentration (Birken and Olendorf, 1989; and references therein).

Electrophysiology. Four male Sprague-Dawley rats weighing $300-$ $400 \mathrm{gm}$ were used for electrophysiological studies. Animals were anesthetized with urethane $1.5 \mathrm{gm} / \mathrm{kg}$ i.p. and placed in a stereotaxic apparatus with their body temperatures maintained at $37^{\circ} \mathrm{C}$ by a feedback heating pad. A $0.5 \times 0.5 \mathrm{~cm}$ craniotomy was made and recording electrodes were placed in the anterior striatum using stereotaxic coordinates and aural monitoring. Following electrode placement the craniotomy was covered with $4 \%$ agar in saline and 30 min were allowed for stabilization before recordings were made. The spontaneous activity of multiple units were recorded extracellularly in the striatum, $1 \mathrm{~mm}$ anterior to the bregma and $3 \mathrm{~mm}$ lateral to the midline at a depth of 3.5 $\mathrm{mm}$ using commercially available tungsten microelectrodes ( $4 \mathrm{M} \Omega$ at 1 $\mathrm{kHz}, \mathrm{F}$. Haer, Inc.). The neuronal activity was amplified, broadcast with an audio monitor, displayed on an oscilloscope, and recorded with a desktop computer. Data acquisition and analysis of mean firing rate was performed using DISCOVERY, EXPERIMENTER'S WORKBENCH, and PERSONAL SCIENTIFIC WORKSTATION software (DataWave Technologies, Longmont, $\mathrm{CO}$ ). We investigated the electrophysiological effects of the NMDA antagonist MK-801 and the NOS inhibitor 7-NI. Initially, baseline spontaneous activity was collected over a $20 \mathrm{~min}$ period for $1 \mathrm{sec}$ every $19 \mathrm{sec}$ ( 60 samples). The animal was then given an i.p. injection of $50 \mathrm{mg} / \mathrm{kg} 7-\mathrm{NI}$. After 60 minutes, an additional $20 \mathrm{~min}$ of spontaneous neuronal activity was collected from the same recording site in the same manner. Finally, spontaneous activity was recorded after the NMDA channel mediated activity was blocked by injection of MK-801 (4 mg/kg).

Statistical methods. Data are expressed as means \pm SEM values. Side-to-side comparisons were made by two-tailed paired $t$ test. The statistical significance of differences in lesion volume, DHBA and nitrotyrosine values, lactate production and ATP depletion between groups were determined by unpaired Student's $t$ test (two tailed) or oncway analysis of variances (ANOVA) followed by Fisher's PLSD (protected least significant difference) post-hoc test to compare group

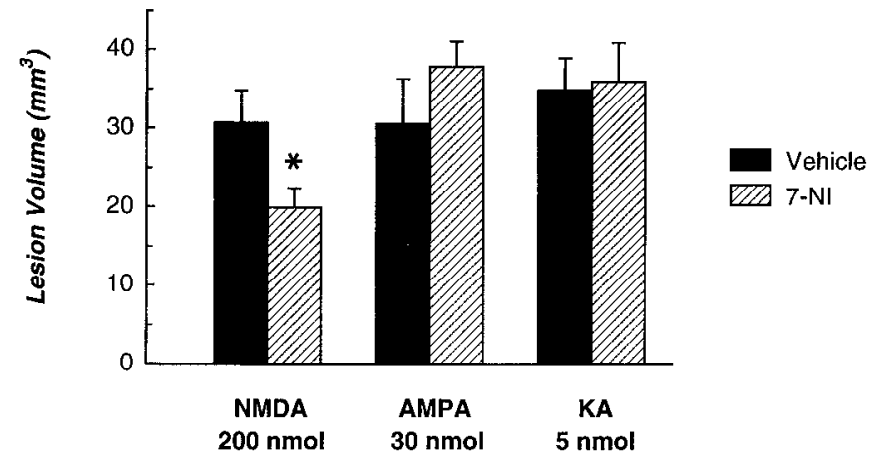

Figure 1. Effects of pretreatment with 7-NI $(2 \times 50 \mathrm{mg} / \mathrm{kg}$ i.p. $)$ on striatal lesions produced by NMDA, AMPA and KA. " $p<0.05$, (Student's $t$ test). Nine to 10 animals were used in each group.

means. The number of animals showing striatal lesions after systemic 3-NP treatment were compared by $\chi^{2}$ test.

Animal guidelines. All animal use procedures were in strict accordance with the NIH Guide for the Care and Use of Laboratory Animals and were approved by the local Animal Care Committee.

\section{Results}

Stereotaxic lesions. We examined whether pretreatment with the neuronal NOS inhibitor 7-nitroindazole (7-NI) can attenuate striatal excitotoxic lesions produced by the excitatory amino acid receptor agonists NMDA, $\alpha$-amino-3-hydroxy-5-methylisoxazole-4-proprionic acid (AMPA), and kainic acid (KA). Pilot experiments showed that a single dose of 7 -NI $(50 \mathrm{mg} / \mathrm{kg}$ i.p. $)$ administered i.p. $0.5 \mathrm{hr}$ before striatal injections produced no protection $\left(200 \mathrm{nmol}\right.$ NMDA $25.0 \pm 2.4 \mathrm{~mm}^{3}$ vs $21.3 \pm 3.4$ $\mathrm{mm}^{3}$ (vehicle vs 7 -NI treatment); $30 \mathrm{nmol}$ AMPA $33.6 \pm 4.6$ $\mathrm{mm}^{3}$ vs $30.4 \pm 5.2 \mathrm{~mm}^{3} ; 5 \mathrm{nmol} \mathrm{KA} 39.5 \pm 2.9 \mathrm{~mm}^{3}$ vs 36.3 $\pm 4.4 \mathrm{~mm}^{3} ; n=9-10$ ). Treatment with two doses of $50 \mathrm{mg} / \mathrm{kg}$ 7-NI $4 \mathrm{hr}$ and $0.5 \mathrm{~h}$ before the striatal injection of the excitotoxins showed significant protection against lesions produced by $200 \mathrm{nmol}$ NMDA (35\%), but no protection against lesions produced by $30 \mathrm{nmol}$ AMPA or 5 nmol KA (Fig. 1).

We and others recently reported that malonate, a reversible inhibitor of succinate dehydrogenase, produces secondary excitotoxic lesions in the striatum (Beal et al., 1993a; Greene et al., 1993; Henshaw et al., 1994). Malonate produces ATP depletions and striatal lesions which are blocked by both competitive and noncompetitive NMDA antagonists (Beal et al., 1993a; Greene et al., 1993; Henshaw et al., 1994). We examined the effects of both $25 \mathrm{mg} / \mathrm{kg}$ and $50 \mathrm{mg} / \mathrm{kg}$ of $7-\mathrm{NI}$ administered i.p. $0.5 \mathrm{hr}$ before striatal injections of $3 \mu \mathrm{mol}$ malonate. 7-NI significantly and dose-dependently attenuated the striatal lesions produced by $3 \mu \mathrm{mol}$ of malonate (Fig. 2, top). Furthermore the administration of L-arginine $(300 \mathrm{mg} / \mathrm{kg}$ i.p. $0.5 \mathrm{hr}$ before the striatal injection) completely blocked the neuroprotective effects of 7-NI whereas D-arginine had no significant effect (Fig. 2, bottom).

Blood pressure and heart rate. To verify that 7-NI was not having effects on endothelial NOS when administered at $50 \mathrm{mg}$ / $\mathrm{kg}$ i.p. blood pressure and heart rate were measured at $30 \mathrm{~min}$ intervals for $180 \mathrm{~min}$ as shown in lable 1. There were no significant effects on heart rate or blood pressure.

ATP and lactate measurements. A possible mechanism for neuroprotective effects of 7-NI would be to prevent the effects of peroxynitrite which can inhibit mitochondrial function (Bolanos et al., 1994), or which can deplete ATP by activation of poly (ADP-ribose) synthetase (Zhang et al., 1994). As compared 


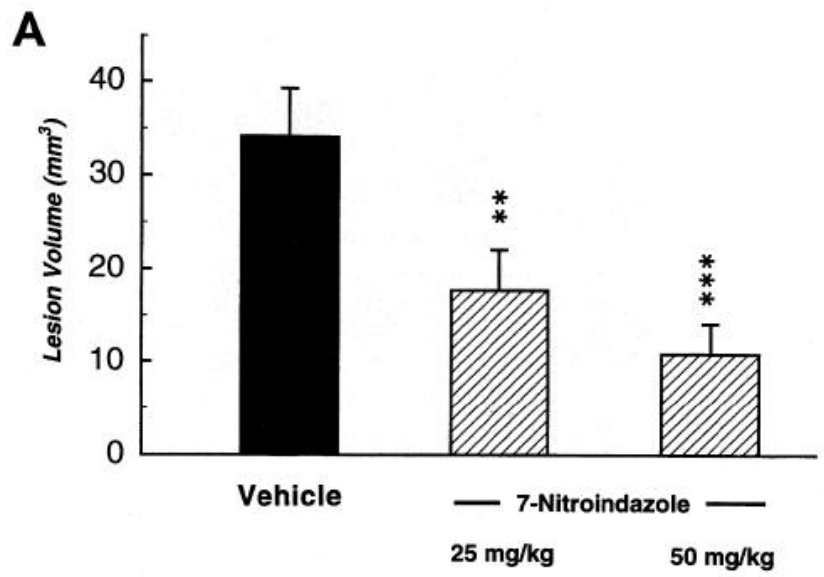

B

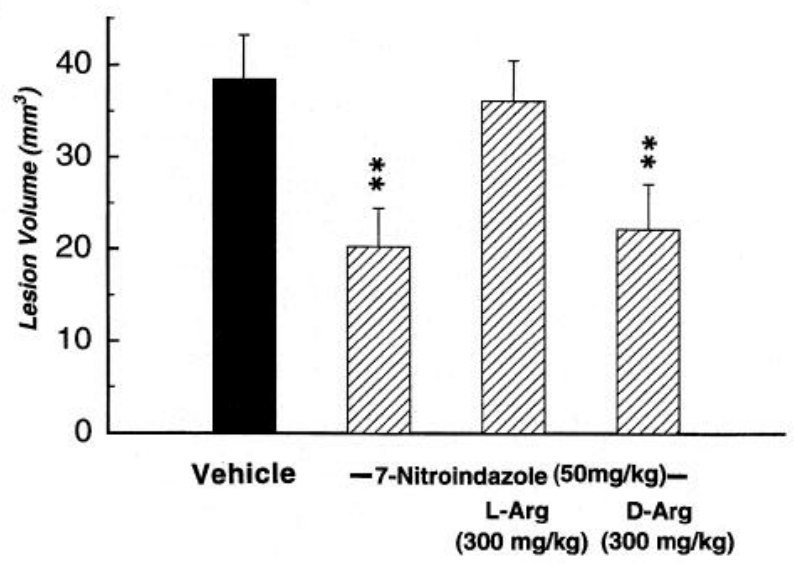

Figure 2. Effects of pretreatment with 7 -NI ( 25 or $50 \mathrm{mg} / \mathrm{kg}$ i.p.) on striatal lesions produced by $3 \mu \mathrm{mol}$ of malonate (top). The effects of $\mathrm{L}$-arginine $(\mathrm{L}-\mathrm{Arg})$ and $\mathrm{D}$-arginine $(D-A r g)$ on the protection produced by $7-\mathrm{NI}(50 \mathrm{mg} / \mathrm{kg}$ i.p. $)$ are shown at the bottom. $* *, p<0.01$; ***, $p$ $<0.001$ (ANOVA). Ten animals were used in each group.

to vehicle treated animals pretreatment with $50 \mathrm{mg} / \mathrm{kg}$ of 7-NI significantly attenuated decreases of striatal ATP concentrations measured $1.5 \mathrm{hr}$ after injections of $3 \mu \mathrm{mol}$ of malonate (Fig. 3). Localized lactate concentrations were measured in vivo using ${ }^{1} \mathrm{H}$ magnetic resonance spectroscopy. There was a profound increase in lactate production $1.5 \mathrm{hr}$ after striatal injection of malonate compared to the contralateral unlesioned striatum (Fig. 3 ). The increased concentrations of lactate after striatal malonate lesions confirm our earlier reports (Beal et al., 1993a; Henshaw et al., 1994), in which we reported similar values. Pretreatment with $50 \mathrm{mg} / \mathrm{kg}$ of 7-NI i.p. $0.5 \mathrm{hr}$ before the striatal lesion significantly attenuated this increase in striatal lactate concentrations (Figs. 3, 4). At $2 \mathrm{hr}$ after striatal injections of malonate in animals treated with 7-NI lesion volumes were significantly attenuated (34.9 $\left.\pm 11.3 \mathrm{~mm}^{3}, n=6\right)$ as compared with vehicle treated controls $\left(84.0 \pm 7.2 \mathrm{~mm}^{3}, n=5, p<0.01\right)$ on $\mathrm{T}_{2}$ weighted MR images (Fig. 4).

Toxicity by systemic 3-NP treatment. Following subacute administration of 3-NP by i.p. injection of $10 \mathrm{mg} / \mathrm{kg}$ every $12 \mathrm{hr}$, rats developed severe dystonic posturing and rigidity by the fourth to fifth day. At these time points basal ganglia lesions were detectable by TTC staining. Vehicle and 7-NI treated animals were sacrificed in pairs at the fourth or fifth day when symptoms developed. Treatment with $25 \mathrm{mg} / \mathrm{kg}$ of 7 -NI every
Table 1. Blood pressure and heart rate after 7-NI administration

\begin{tabular}{rll} 
Time & $\begin{array}{l}\text { Mean arterial } \\
\text { blood pressure } \\
\text { (MAP) } \\
(\mathrm{mm})\end{array}$ & $\begin{array}{l}\text { Heart rate }(\mathrm{HR}) \\
\text { (beats/min) }\end{array}$ \\
\hline 0 & $111 \pm 3$ & $342 \pm 11$ \\
30 & $111 \pm 3$ & $330 \pm 9$ \\
60 & $111 \pm 2$ & $354 \pm 9$ \\
90 & $110 \pm 3$ & $348 \pm 6$ \\
120 & $112 \pm 3$ & $358 \pm 15$ \\
180 & $108 \pm 2$ & $349 \pm 10$
\end{tabular}

Data are expressed as means $\pm \operatorname{SEM}(n=6)$. The 0 min time point is just prior to i.p. injection of $50 \mathrm{mg} / \mathrm{kg}$ 7-NI dissolved in peanut oil. ANOVA for repeated measurements did not show a significant change in mean arterial blood pressure or heart rate over time. MAP: $F(5,5,25)=0.285, p=0.917$; HR: $F(5,5,25)=1.364, p=0.2714$.

$12 \mathrm{hr}$ completely prevented striatal lesions produced by 3-NP (Fig. 5).

We carried out a similar experiment for histologic evaluation and immunocytochemistry for 8-hydroxy-2-deoxyguanosine and 3-nitrotyrosine. 8-hydroxy-2-deoxyguanosine is a well accepted marker of oxidative damage to DNA (Park et al., 1992; Mecocci et al., 1993), while 3-nitrotyrosine is produced by peroxynitritemediated tyrosine nitration (Ischiropoulos et al., 1992). 3-NP (10 $\mathrm{mg} / \mathrm{kg}$ ) was administered every $12 \mathrm{hr}$. Vehicle and 7-NI treated animals were sacrificed in pairs $(n=5)$. Since the first experiment showed complete protection a second group of 7-NI treated animals was included. These animals were not sacrificed in pairs with the controls, but only later when they became symptomatic. Controls were sacrificed after a median cumulative 3-NP dose of $80 \mathrm{mg} / \mathrm{kg}$ (range $70-90 \mathrm{mg} / \mathrm{kg}$ ), whereas the $7-\mathrm{NI}$ treated animals first showed systemic toxicity after a median cumulative dose of $130 \mathrm{mg} / \mathrm{kg}$ (range $90-130 \mathrm{mg} / \mathrm{kg}, p<0.02$, MannWhitney $U$ test). The animals treated with 3 -NP and vehicle showed extensive bilateral lesions in the striatum. Nissl stains

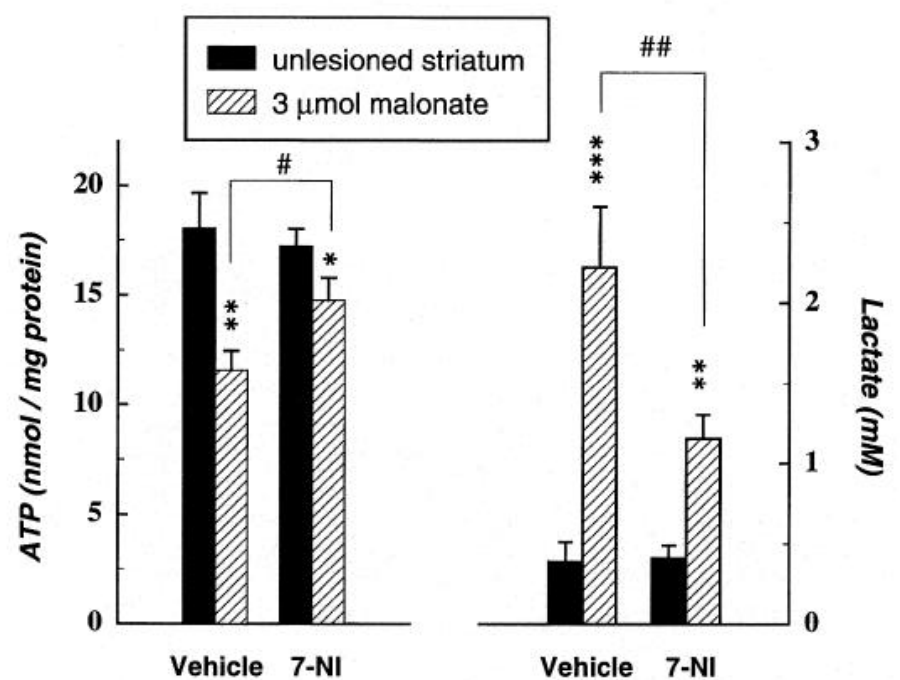

Figure 3. Effects of treatment with $50 \mathrm{mg} / \mathrm{kg}$ of 7-NI on ATP depletions at $3 \mathrm{hr}(n=8)$ and lactate increases detected by ' $\mathrm{H}$ magnetic resonance spectroscopy at $1.5 \mathrm{hr}(n=5-6)$ induced by malonate. *, $p$ $<0.05 ; * *, p<0.01 ; * * *, p<0.001$ as compared with the unlesioned striata (paired Student's $t$ test). \#, $p<0.05$; \#, $p<0.01$ (unpaired Student's $t$ test). 

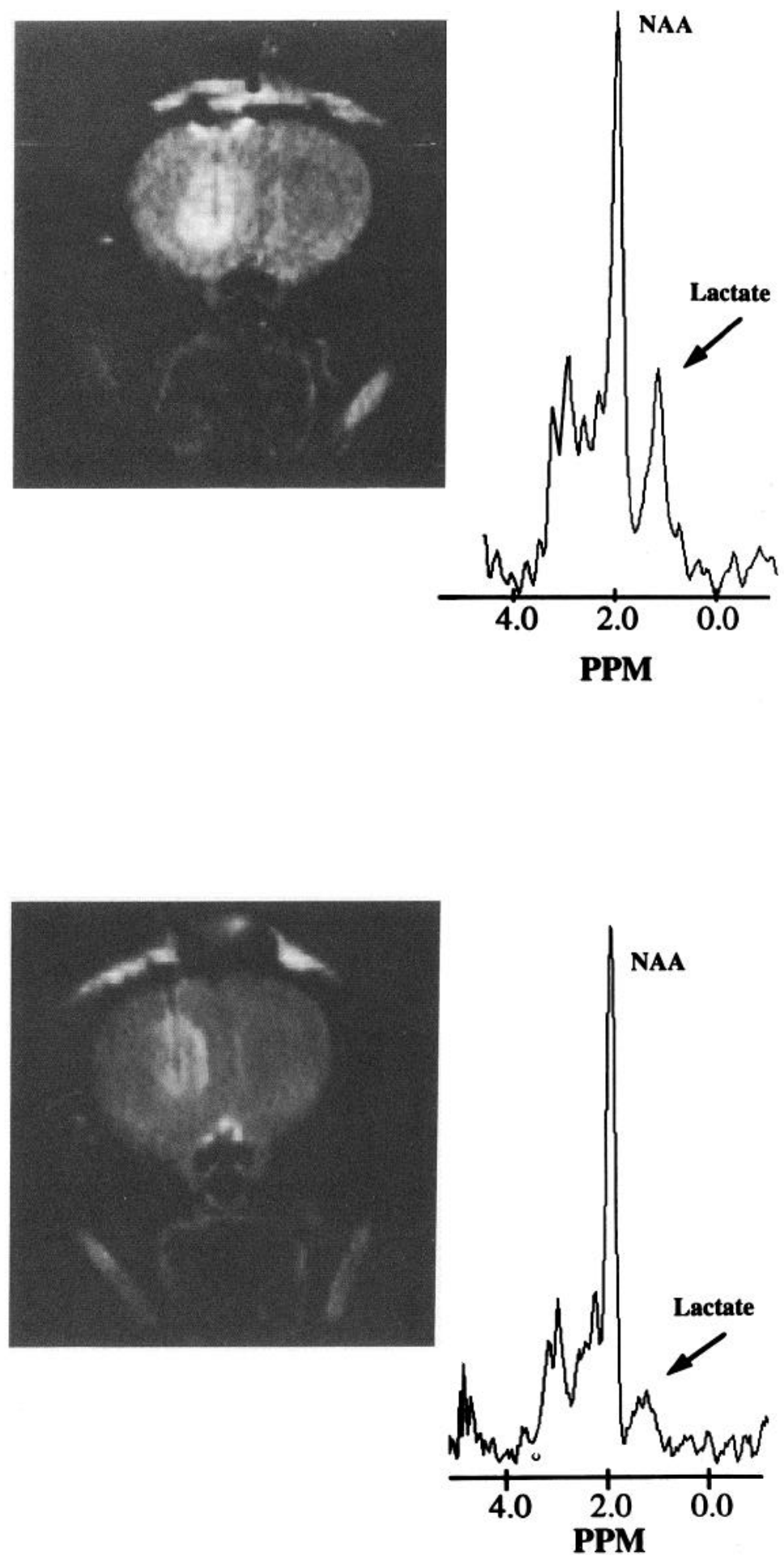

Figure 4. $\mathrm{T}_{2}$-weighted images (TR $3200 /$ TE 80 ) and striatal proton spectra from two lines of a one dimensional chemical shift imaging sequence (magnitude spectrum TR 2200/TE 272) in a rat $1.5 \mathrm{hr}$ after striatal injection of 3 $\mu \mathrm{mol}$ malonate without (upper panel) and with pretreatment of $50 \mathrm{mg} / \mathrm{kg}$ of 7-NI (lower panel). Rats were imaged on a 4.7-T General Electric Omega CSI Imager with a $30 \mathrm{~mm}$ bird-cage coil. $N A A, \quad \mathrm{~N}$-acetylaspartate; $P P M$, parts per million.

showed loss of neurons with relative sparing of NADPH-diaphorase positive neurons (Fig. 6). In animals concomitantly treated with 3-NP and 7-NI with either dosing regimen, 7-NI completely protected the striatum from lesions and there was no immunoreactivity for either 8-hydroxy-2-deoxyguanosine or 3-nitrotyrosine. Compared to saline treated controls and 7-NI treated 3-NP animals there was a marked increase of 8-hydroxy2-deoxyguanosine and 3-nitrotyrosine immunoreactivity in vehicle treated 3-NP animals (Fig. 7). Treatment with 7-NI alone had no effect on immunocytochemistry in animals not receiving
3-NP. Biochemical measurements of 8-hydroxy-2-deoxyguanosine confirmed that it was increased from $9.1 \pm 3.1$ to $44.1 \pm$ $8.0 \mathrm{fmol} / \mu \mathrm{g}$ DNA $(p<0.001)$ following 3-NP treatment.

Measurements of DHBA and 3-nitrotyrosine in 3-NP toxicity. The concentrations of 2,3 and 2,5 DHBA, which are formed by salicylate reacting with $\mathrm{OH}$ radicals, were significantly increased following intrastriatal injection of NMDA and 2,5 DHBA was increased by KA injections (Fig. 8). 7-NI treatment significantly $(p<0.05)$ attenuated the increase in 2,5 DHBA produced by NMDA. The concentrations of 2,3 and 2,5 DHBA, 


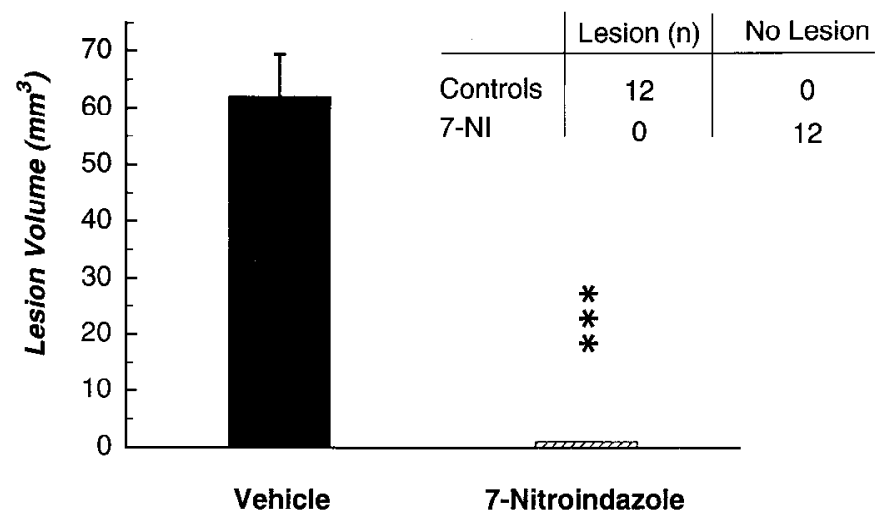

Figure 5. Fffects of 7-NI on striatal lesions produced hy i.p. injection of $10 \mathrm{mg} / \mathrm{kg}$ of 3-NP every $12 \mathrm{hr}$. Animals were treated with either 25 $\mathrm{mg} / \mathrm{kg} 7$-NI or vehicle at the same time points. Animals were sacrificed at the 4 th and 5 th day. The table gives the number of animals showing a striatal lesion per group ( $n=12, p<0.001$ by $\chi^{2}$ test). For calculation of lesion volume the lesions in both hemispheres were combined. ***, $p<0.001$ (Student's $t$ test). Twelve amimals per group were used.

were significantly increased after 3-NP treatment as compared to saline treated controls (Fig. 9). Treatment of 3-NP animals with 7-NI significantly attenuated the increase of 2,3 DHBA. Peroxynitrite, a product of $\mathrm{NO}^{-}$reaction with $\mathrm{O}_{2} \cdot$, has recently been defined as a potent oxidant (Beckman et al., 1990) and mediates the nitration of tyrosine (Beckman et al., 1992; Ischiropoulos et al., 1992). Both intrastriatal injection of NMDA and KA siginficantly increased the ratio of 3-nitrotyrosine to tyrosine in the striatum and the increases produced by NMDA but not KA were blocked by 7-NI pretreatment (Fig. 8). 3-NP treatment increased the ratio of 3-nitrotyrosine to tyrosine in the striatum compared to saline treated controls. Treatment with 7-NI significantly attenuated the increase of 3-nitrotyrosine as compared to vehicle treated animals in 3-NP animals (Fig. 9).

Electrophysiology. The effects of 7-NI on spontaneous striatal electrophysiologic activity were compared with those of the NMDA antagonist MK-801 in urethane anesthetized rats, to determine whether 7-NI could antagonize NMDA excitatory amino acid receptors. Spontaneous electrophysiologic activity of neurons returned to normal within $30 \mathrm{~min}$ after insertion of an electrode into the striatum. After stabilization the mean spontaneous firing rate in the striatum was recorded (Fig. 10). Sixty minutes after i.p. treatment with $50 \mathrm{mg} / \mathrm{kg}$ of 7 -NI the mean spontaneous firing rate was not significantly different from the spontanous firing rate of untreated controls. To demonstrate that the NMDA channels were still functional after treatment with 7-NI, animals were then given the NMDA antagonist MK-801. This produced a decrease in mean firing rate which was rapid and profound (Fig. 10), suggesting that the effects of 7-NI were not mediated by an interaction with excitatory amino acid receptors.

\section{Discussion}

The role of nitric oxide in neuronal injury both in vitro and in vivo has been controversial (Dawson and Snyder, 1994). Much of this controversy may be due to the nonspecificity of NOS inhibitors for various isoforms of NOS. Three major isoforms have been indentified which are the constituative neuronal and endothelial forms, and the inducible form produced by macrophages. 7-Nitroindazole has a high degree of specificity for the neuronal isoform of NOS in vivo (Babbedge et al., 1993; Moore et al., 1993; Yoshida et al., 1994). It produces no effects on blood pressure yet it has antinociceptive effects, and it inhibits brain NOS activity (Babbedge et al., 1993; Connop et al., 1994; Yoshida et al., 1994). In vitro studies show that it will inhibit both endothelial NOS and macrophage inducible NOS (Wolff et al., 1994), suggesting that compartmentalization or metabolism may contribute to its selectivity in vivo. It acts as an inhibitor by competing with $\mathrm{L}$-arginine for binding to the prosthetic heme group of NOS, and it additionally affect the pteridine site of the enzyme (Mayer et al., 1994).

Recent evidence has implicated neuronal NOS in both focal ischemic lesions (Huang et al., 1994; Yoshida et al., 1994), and in MPTP induced toxicity to dopaminergic neurons (Schulz et al., 1995b). In the present study we examined the role of NO* in excitotoxic neuronal injury in vivo by determining whether inhibition of neuronal NOS with 7-NI could attenuate lesions produced by NMDA, kainic acid or AMPA. Lesions produced by NMDA were significantly attcnuated whercas there was no effect on lesions produced by either kainic acid or AMPA. These results are consistent with those of Dawson and colleagues in vitro (Dawson et al., 1991; 1993). They found that nitric oxide synthase inhibitors, and hemoglobin, which binds $\mathrm{NO}^{\circ}$, could protect against both glutamate and NMDA neurotoxicity, yet there was no effect on kainate toxicity. A small protection was observed against quisqualate, but it was thought that this might relate to a portion of quisqualate toxicity occurring via NMDA receptor activation. Similarly another study showed no effect of NOS inhibitiors on KA and AMPA neurotoxicity in vitro (Garthwaite and Garthwaite, 1994). Subsequent studies showed that treatment of cultures with low doses of quisqualate, which preferentially kills nitric oxide synthase containing neurons, blocked glutamate neurotoxicity in cultured cortical and striatal neurons (Dawson et al., 1993). These results have been replicated in some studies (Izumi et al., 1992; Vigé et al., 1993) but not in others (Demerlé-Pallardy et al., 1991; Pauwels and Leysen, 1992; Hewett et al., 1993; Regan et al., 1993; Zinkand et al., 1993; Garthwaite and Garthwaite, 1994) Results in vivo were also inconsistent in protecting hippocampal neurons from NMDA neurotoxicity (Haberny et al., 1992; Lerner-Natoli et al., 1992; Moncada et al., 1992).

The present results show that an inhibitor of neuronal NOS can produce significant protection against NMDA mediated excitotoxic lesions, but not against those produced by kainic acid or AMPA, consistent with results in vitro (Dawson et al., 1991; Dawson et al., 1993) The selectivity for NMDA mediated excitotoxic lesions may be related to the calcium conductance of the NMDA receptor. The entry of calcium through NMDA receptor channels into cells stimulates NOS by binding to calmodulin, which is a cofactor for NOS (Bredt and Snyder, 1990).

In the present study we provide the first evidence that inhibition of neuronal NOS can attenuate striatal lesions produced by either intrastriatal administration of malonate or systemic administration of 3-NP. We and others found that both malonate and 3-NP produce striatal lesions by a secondary excitotoxic mechanism as a consequence of impairment of energy metabolism (Beal et al., 1993a; Greene et al., 1993; Henshaw et al., 1994). Interestingly 7-NI was much more effective against these secondary excitotoxic lesions than it was against the excitotoxin NMDA. 7-NI produced almost complete protection against 3-NP neurotoxicity, which is the best neuroprotection we have achieved with any compound against this type of lesion (Schulz and Beal, unpublished results). To further investigate the specificity of the effects of 7-NI we showed that L-arginine but not 

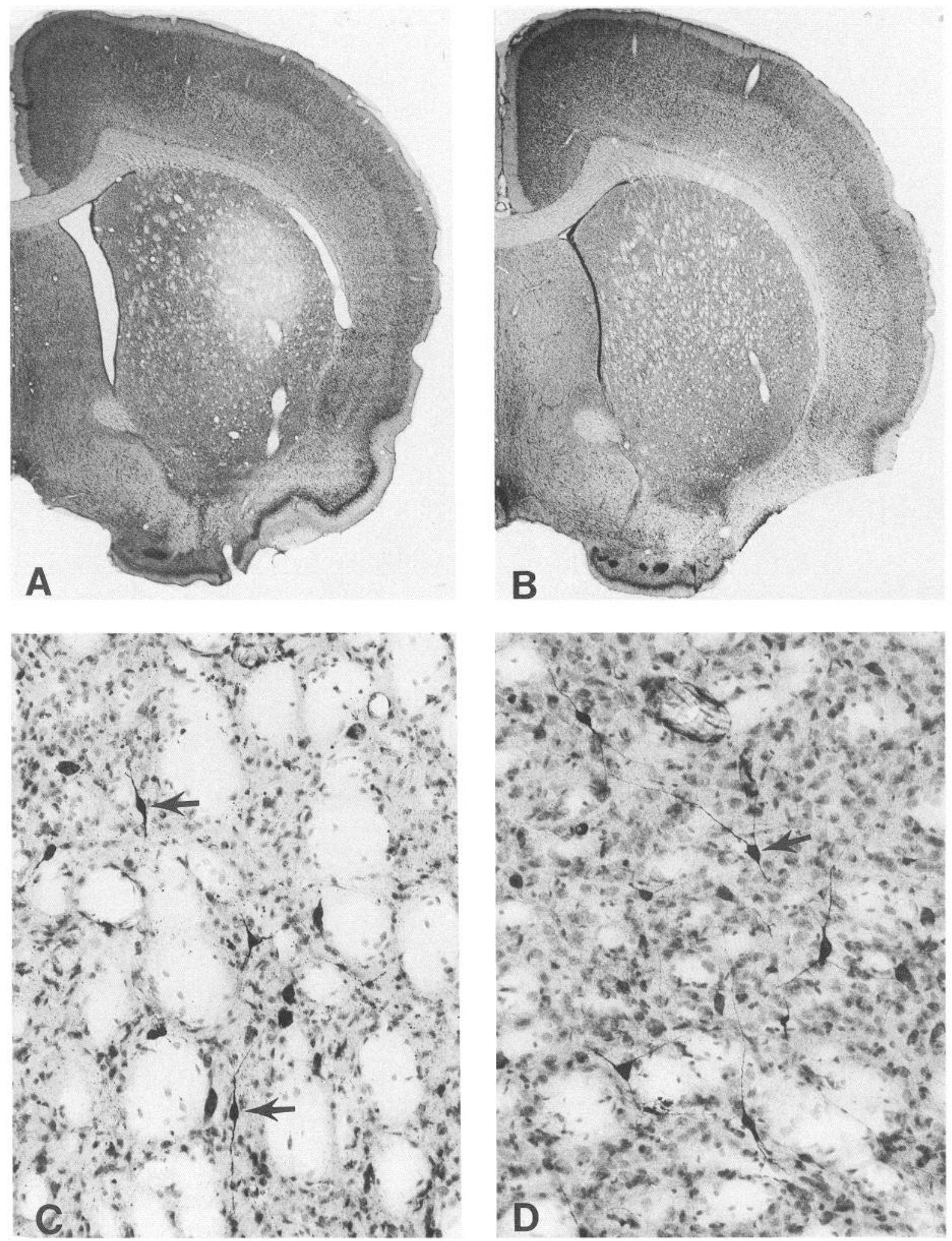

Figure 6. Photomicrographs of the neostriatal neurotoxic lesion as a consequence of the subcutaneous administration of the succinate dehydrogenase inhibitor, 3-NP, in $A$ and $C$. Tissue sections are double stained with Nissl and for NADPH-diaphorase. The striatal lesion is represented by staining pallor in the dorso-lateral quadrant $(A)$. The lesion is characterized by marked neuronal loss and gliosis with a relative preservation of NADPH-diaphorase neurons (arrows) $(C)$. Concomitant subcutaneous injection of the nitric oxide inhibitor, 7-NI, with 3-NP resulted in complete protection against striatal lesions $(B$ and $D)$ as compared to the 3-NP lesion. 

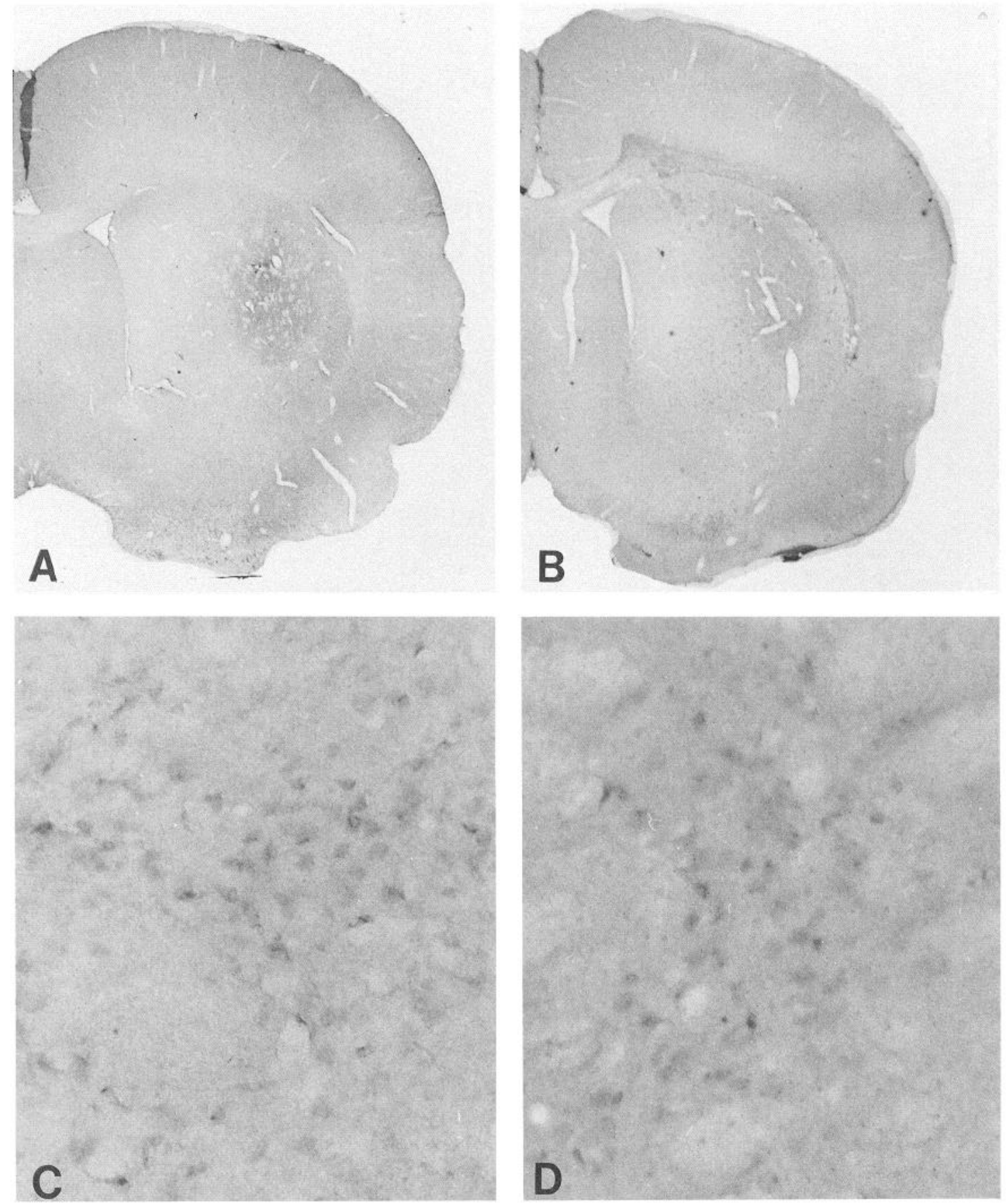

Figure 7. Photomicrograph of 3-NP treated rats which resulted in increased immunocytochemical activity for 8-hydroxy-2-deoxyguanosine in $A$ and $C$ and nitrotyrosine in $B$ and $D$. The increased immunohistochemical activity corresponds to the lesion area observed in Figure $6 A$ in both $A$ and $B$, with cellular localization in $C$ and $D$.

D-arginine would reverse its protective effects against malonate lesions. This is consistent with the findings of Yoshida et al. (1994) in focal ischemic lesions. We also found that 7-NI had no effects on blood pressure and heart rate at the doses used in the present experiments, consistent with a relatively selective effect on neuronal NOS in vivo.

We investigated the mechanism of the neuroprotective effects of 7-NI. 7-NI had no effect on spontaneous electrophysiologic activity in rat striatum in vivo, while MK-801 inhibited activity. This suggests that 7-NI does not act at NMDA receptors. We also examined whether 7-NI could attenuate ATP depletions and increases in lactate concentrations produced by intrastriatal administration of malonate. Interestingly 7-NI attenuated both ATP depletions and increases in lactate. The latter result was also confirmed using ' $\mathrm{H}$ magnetic resonance spectroscopy in vivo. This result contrasts with those of a free radical spin trap which exerted neuroprotective effects but had no effect on malonate induced depletions of ATP (Schulz et al., 1995). One possible explanation for this is that an inhibition of $\mathrm{NO}^{-}$production may prevent DNA damage, and activation of poly ADP-ribose poly- 


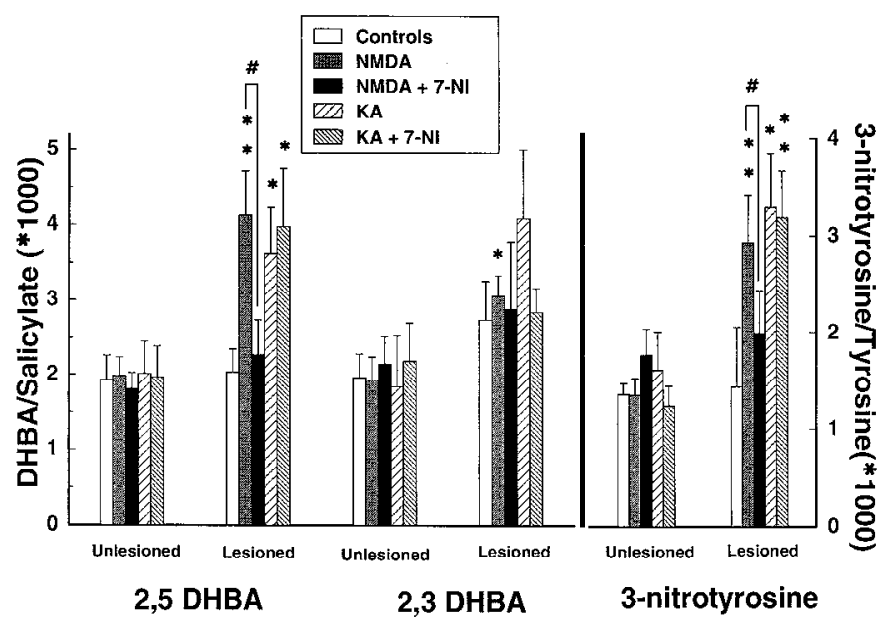

Figure 8. Production of 2,3 and 2,5 DHBA and 3-nitrotyrosine following intrastriatal injection of NMDA and KA and effects of 7-NI. NMDA significantly increased 2,3 and 2,5 DHBA and 3-nitrotyrosine as compared with controls, while KA significantly increased both 2,5 DHBA and 3-nitrotyrosine $(*, p<0.05 ; * *, p<0.01$ as compared with saline controls, ANOVA). An increase of 2,3 DHRA produced by KA was not quite significant $(p<0.07)$. 7-NI significantly attenuated increases in 2,5 DHBA and 3-nitrotyrosine produced by NMDA but not by $\mathrm{K} \Lambda$ ( $\#, p<0.05$ as compared with NMD $\Lambda$ treated animals, $\Lambda \mathrm{NO}$ VA).

merase which then leads to both ATP and NAD depletion, followed by cell death (Zhang et al., 1994). Consistent with this possibility we found that 3-NP treatment leads to oxidative damage to DNA as shown by increases in 8-hydroxy-2-deoxyguanosine measurements and 8-hydroxy-2-deoxyguanosine immunohistochemistry. $\mathrm{NO}^{*}$ can inhibit cytochrome $\mathrm{c}$ oxidase in vitro, and deenergize mitochondria (Bolanos et al., 1994; Cleeter et al., 1994; Schweizer and Richter, 1994). Peroxynitrite also inhibits the mitochondrial respiratory chain in cultured neurons (Bolanos et al., 1995).

We examined the effects of 7-NI on increases in 2,3 and 2,5 DHBA and 3-nitrotyrosine in vivo. ${ }^{\circ} \mathrm{OH}$ radical generation results in an increase in the conversion of salicylate to 2,3 and 2,5

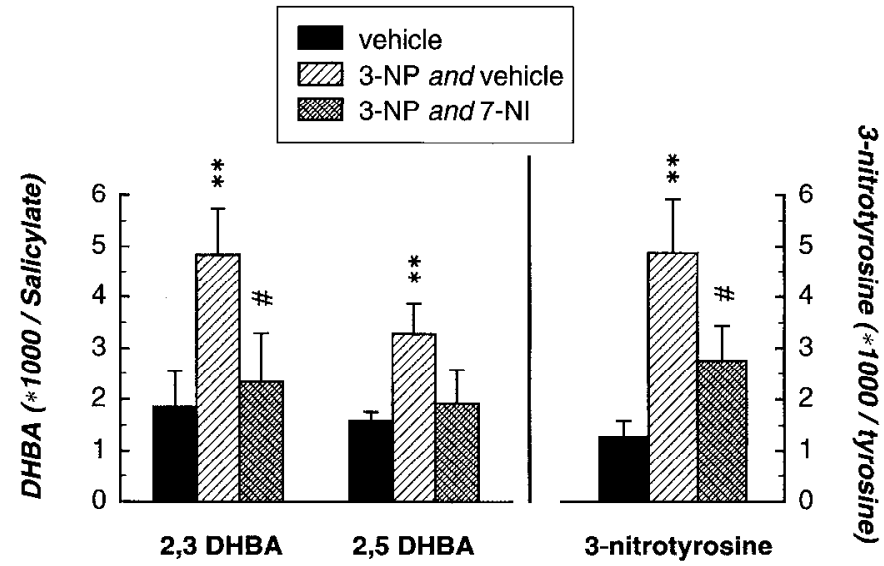

Figure 9. Production of 2,3 and 2,5 DHBA and 3-nitrotyrosine by systemic treatment with $3-\mathrm{NP}$ and effects of 7 -NI. Intraperitoneal injections of 3-NP significantly increased concentrations of 2,3 and 2,5 DHBA and of 3-nitrotyrosine (**, $p<0.01$ as compared to saline treated controls, ANOVA). These increases were significantly attenuated by 7 -NI (\#, $p<0.05$ as compared to $3-\mathrm{NP}$ and vehicle treated animals, ANOVA). Ten animals were used per group.
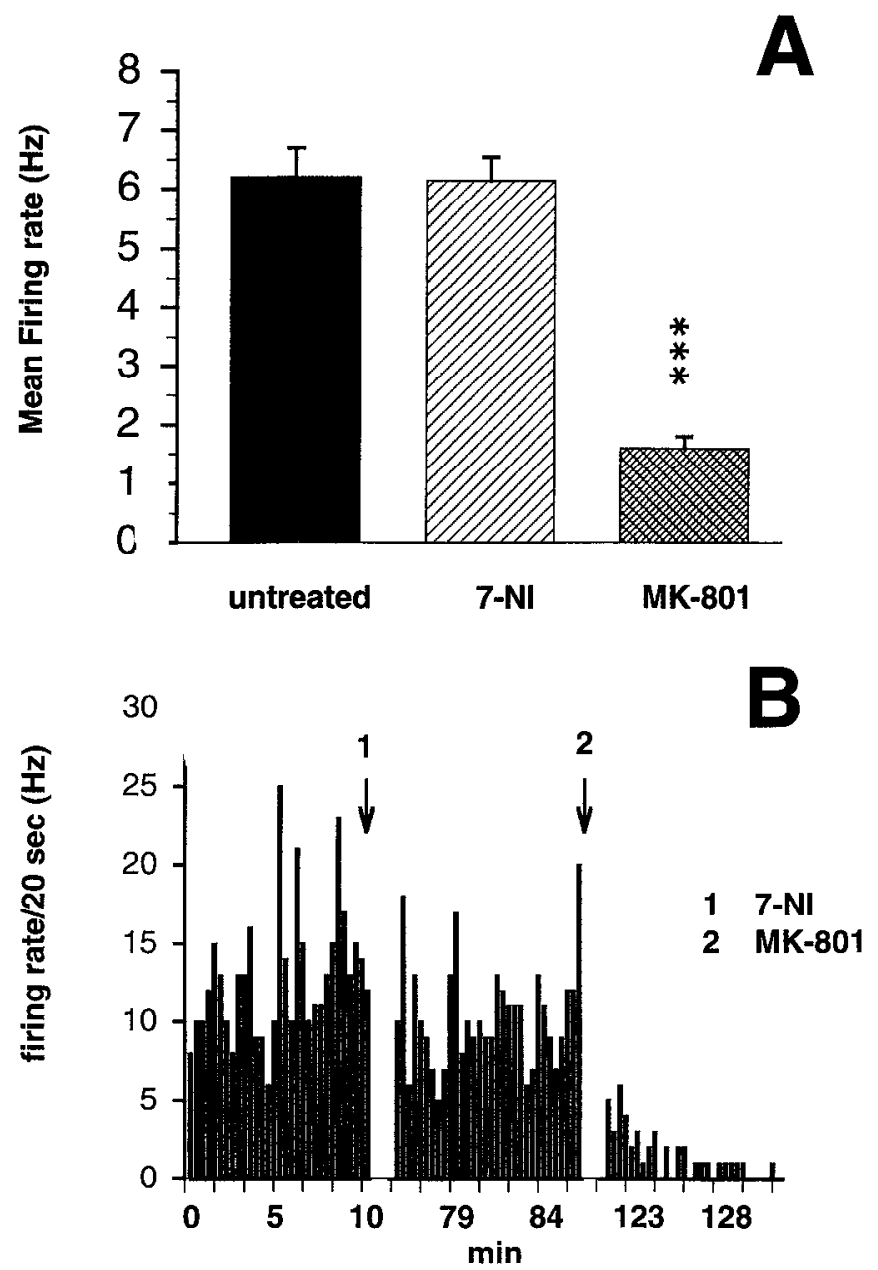

Figure 10. Electrophysiologic effects of 7-NI in the striatum in vivo. $A$, The graph illustrates the mean spontaneous firing rate, after injection of 7-NI $(50 \mathrm{mg} / \mathrm{kg}$ i.p.), and after injection of MK-801 (4 mg/kg i.p.). Four animals received 7-NI and three of these also received MK-801. The spike counts were averaged. $* * *, p<0.001$ compared to the spontaneous firing rate and after treatment with 7-NI (ANOVA). B, Actual firing rate of neurons in the striatum from one of these animals. The baseline spontaneous activity was recorded between 0 and $16 \mathrm{~min}$. The first gap in the graph represents 60 min which elapsed from the time when the animal was injected with 7-NI (arrow 1). During this gap no change in activity occurred. The second gap indicates the $30 \mathrm{~min}$ that passed after administering the MK-801 (arrow 2).

DHBA (Floyd et al., 1984; Hall et al., 1993). In the present study we found that both NMDA and KA produced increases in $\cdot \mathrm{OH}$ radical generation and 3-nitrotyrosine. The increases produced by NMDA were altenuated by pretrealment with 7 -NI, consistent with its protective effect, whereas 7-NI had no effect on increases produced by KA. The explanation for the lack of an effect of KA induced increases is unclear, but may be due to compartmentalization of calcium fluxes, as suggested in vitro (Tymianski et al., 1993). 3-NP produced increases in both 2,3 and 2,5 DHBA/salicylate, which were attenuated by pretreatment with 7-NI. Furthermore we found that 3 -NP produced increases in 3-nitrotyrosine concentrations and in immunocytochemical staining for 3 nitrotyrosine which were attenuated by prior treatment with 7-NI.

These results suggest that peroxynitrite may play a role in both NMDA and 3-NP induced neurotoxicity in vivo. Peroxynitrite is formed by the reaction of $\mathrm{NO}^{*}$ with superoxide radical 
(Beckman et al., 1992; Ischiropoulos et al., 1992). 'Ihis reaction occurs at an extremely fast rate of $6.7 \times 10^{9} \mathrm{M}^{-1} \mathrm{sec}^{-1}$ and does not requirc transition metals. Pcroxynitrite may decompose to form $\mathrm{OH}$ radical, nitrogen dioxide, and nitronium ions which can nitrate tyrosines (Beckman et al., 1990, 1992; Ischiropoulos et al., 1992; Crow et al., 1994; van der Vliet et al., 1994). Our findings that both NMDA and 3-NP produce an increase in ${ }^{\circ} \mathrm{OH}$ radical generation and in 3-nitrotyrosine are therefore consistent with a role of peroxynitrite in NMDA and 3-NP neurotoxicity. The histolugic results showing that 3-NP produces increased staining for 8-hydroxy-2-deoxyguanosine, a marker of $\mathrm{OH}^{\cdot}$ radical damage to DNA, and 3-nitrotyrosine also suggests a role of peroxynitrite in the pathogenesis of the lesions.

The present results provide evidence that $\mathrm{NO}^{*}$ plays a role in NMDA, malonate and 3-NP neurotoxicity in vivo. We recently reported that 7-NI protects against MPTP neurotoxicity in mice, which is a model for Parkinson's disease (PD) (Schulz et al., 1995b). Similarly lesions produced by malonate and 3-NP in both rats and non-human primates closely resemble the histologic, neurochemical and clinical features of HD (Beal et al., 1993a,b; Brouillet et al., 1995; Greene et al., 1993; Henshaw et al., 1994). The present results implicate NO* in the pathogenesis of these lesions. As such these results suggest that treatment with specific inhibitors of neuronal NOS may prove efficacious in the treatment of neurodegenerative diseases, such as HD and PD.

\section{References}

Babbedge RC, Bland-Ward PA, Hart SL, Moore PK (1993) Inhibition of rat cerebellar nitric oxide synthase by 7-nitro indazole and related substituted indazoles. Br J Pharmacol 110:225-228.

Beal MF (1992) Does impairment of energy metabolism result in excitotoxic neuronal death in neurodegenerative illnesses? Ann Neurol 31:119-130.

Beal MF, Matson WR, Swartz KJ, Gamache PH, Bird ED (1990) Kynurenine pathway measurements in Huntington's disease striatum: evidence for reduced formation of kynurenic acid. $\mathbf{J}$ Neurochem 55 $1327-1339$.

Beal MF, Ferrante RJ, Swartz KJ, Kowall NW (1991) Chronic quinolinic acid lesions in rats closely resemble Huntington's disease. J Neurosci 11:1649-1659.

Beal MF, Brouillet E, Jenkins B, Henshaw R, Rosen B, Hyman BT (1993a) Age-dependent striatal excitotoxic lesions produced by the endogenous mitochondrial inhibitor malonate. J Neurochem 61: 1147-1150.

Beal MF, Brouillet E, Jenkins BG, Ferrante RJ, Kowall NW, Miller JM, Storey E, Srivastava R, Rosen BR, Hyman BT (1993b) Neurochemical and histological characterization of striatal excitotoxic lesions produced by the mitochondrial toxin 3-nitropropionic acid. J Neurosci $13: 4181-4192$.

Beckman JS, Beckman TW, Chen J, Marshall PM, Freeman BA (1990) Apparent hydroxyl radical production by peroxynitrite: implications for endothelial injury from nitric oxide and superoxide. Proc Natl Acad Sci USA 87:1621-1624.

Beckman JS, Ischiropoulos H, Zhu L, van der Woerd M, Smith C, Chen J, Harrison J, Martin JC, Tsai M (1992) Kinetics of superoxide dismutase- and iron-catalazed nitration of phenolics by peroxynitrite. Arch Biochem Biophys 298:438-445.

Beckman JS, Ye YZ, Anderson PG, Chen J, Accavitti MA, Tarpey MM, White CR (1994) Extensive nitration of protein tyrosines in human atherosclerosis detected by immunohistochemistry. Biol Chem Hoppe-Seyler 375:81-88.

Bederson JB, Pitts LH, Germano SM, Nishimura MC, Davis RL, Bartkowski HM (1986) Evaluation of 2,3,5-triphenyltetrazolium chloride as a stain for detection and quantification of experimental cerebral infarction in rats. Stroke 17:1304-1308.

Birken DL, Olendorf WH (1989) N-Acetylaspartic acid review of a compound prominent in ' $\mathrm{H}$ NMR spectroscopy. Ncurosci Biobchav Rev 4:7-18.

Bolanos JP, Peuchen S, Heales SJR, Land JM, Clark JB (1994) Nitric oxide-mediated inhibition of the mitochondrial respiratory chain in cultures astrocytes. J Neurochem 63:910-916.

Bolanos JP, Heales SJR, Land JM, Clark JB (1995) Effect of peroxynitrite on the mitochondrial respiratory chain: differential susceptibility of neurones and astrocytes in primary culture. $J$ Neurochem 64:1965-1972.

Bredt DS, Snyder SH (1990) Isolation of nitric oxide synthase, a calmodulin-requiring enzyme. Proc Natl Acad Sci USA 87:682-685.

Brouillet E, Jenkins BG, Hyman BT, Ferrante RI, Kowall NW, Srivastava R, Roy DS, Rosen BR, Beal MF (1993b) Age-dependent vulnerability of the striatum to the mitochondrial toxin 3-nitropropionic acid. J Neurochem 60:356-359.

Brouillet E, Hantraye P, Ferrante RJ, Dolan R, Leroy-Willig A, Kowall NW, Beal MF (1995) Chronic mitochondrial energy impairment produces selective striatal degeneration and abnormal choreiform movements in primates. Proc Natl Acad Sci USA 92:7105-7109.

Cleeter MWJ, Cooper JM, Darley-Usmar VM, Moncada S, Schapira AHV (1994) Reversible inhibition of cytochrome c oxidase, the terminal enzyme of the mitochondrial respiratory chain by nitric oxide. FEBS Lett 345:50-54.

Connop BP, Rolfe NG, Boegman RJ, Jhamandas K, Beninger RJ (1994) Potentiation of NMDA-mediated toxicity on nigrostriatal neurons by a low dose of 7-nitro-indazole. Neuropharmacology 33:1439-1445.

Crow JP, Spruell C, Chen J, Gunn C, Ischiropoulos H, Tsai M, Smith CD, Radi R, Koppenol WH, Beckman JS (1994) On the pH-dependent yield of hydroxyl radical products from peroxynitrite. Free Radic Biol Med 16:331-338.

Dawson TM, Snyder SH (1994) Gases as biological messengers: nitric oxide and carbon monoxide in the brain. J Neurosei 14:5147-5199.

Dawson VL, Dawson TM, London ED, Bredt DS, Snyder SH (1991) Nitric oxide mediate glutamate neurotoxicity in primary cortical culture. Proc Natl Acad Sci USA 88:6368-6371.

Dawson VL, Dawson TM, Bartley DA, Uhl GR, Snyder SH (1993) Mechanisms of nitric-oxide mediated neurotoxicity in primary brain cultures. J Neurosci 13:2651-2661.

Demerlé-Pallardy C, Lonchampt MO, Chabrier PE, Braquet P (1991) Absence of implication of L-arginine/nitric oxide pathway on ncuronal cell injury induced by L-glutamate or hypoxia. Biochem Biophys Res Commun 181:456-464.

Floyd RA, Watson JJ, Wong PK (1984) Sensitive assay of hydroxyl radical formation utilizing high pressure liquid chromatography with electrochemical detection of phenol and salicylate hydroxylation products. J Biochem Biophys Methods 10:221-235.

Garthwaite G, Garthwaite J (1994) Nitric oxide does not mediate acute ghitamate neurotoxicity, nor is it neuroprotective, in rat brains slices. Neuropharmacology 33:1431-1438.

Greene JG, Porter RHP, Eller RV, Greenamyre JT (1993) Inhibition of succinate dehydrogenase by malonic acid produces an excitotoxic lesion in rat striatum. J Neurochem 61:1151-1154.

Haberny KA, Pou S, Eccles CU (1992) Potentiation of quinolinateinduced hippocampal lesions by inhibition of NO synthesis. Neurosci Lett 146:187-190.

Hall ED, Andrus PK, Yonkers PA (1993) Brain hydroxyl radical generation in acute experimental head injury. J Neurochem 60:588-594.

Henshaw R, Jenkins BG, Schulz JB, Ferrante RJ, Kowall NW, Rosen BR, Beal MF (1994) Malonate produces striatal lesions by indirect NMDA receptor activation. Brain Res 647:161-166.

Hewett SJ, Corbett JA, McDaniel ML, Choi DW (1993) Inhibition of nitric oxide formation does not protect murine cortical cell cultures from $N$-methyl-D-aspartate neurotoxicity. Brain Res 625:337-341.

Huang Z, Huang PL, Panahian N, Dalkara T, Fishman MC, Moskowitz MA (1994) Effects of cerebral ischemia in mice deficient in neuronal nitric oxide synthase. Science 265:1883-1885.

Ischiropoulos H, Zhu L, Chen J, Tsai M, Martin JC, Smith CD, Beckman JS (1992) Peroxynitrite-mediated tyrosine nitration catalyzed by superoxide dismutase. Arch Biochem Biophys 298:431-437.

Izumi Y, Benz AM, Clifford DB, Zorumski CF (1992) Nitric oxide inhibitors atteuate $N$-methyl-D-aspartate excitotoxicity in rat hippocampal slices. Neurosci Lett 135:227-230.

Jenkins BG, Storey E, Beal MF, Rosen BR (1991) Chemical shift imaging of focal neurochemical lesions in rat brain. Proc Soc Magnetic Res Med 1:437.

Lerner-Natoli M, Rondouin G, de Bock F, Bockaert J (1992) Chronic NO synthase inhibition fails to protect hippocampal neurons against NMDA toxicity. Neuroreport 3:1109-1112. 
Lust WD, Feussner GK, Barbehenn EK, Passoneau JV (1981) The enzymatic measurements of adenine nucleotides and P-creatinine in picomole amounts. Anal Biochem 110:258-266.

Mayer B, Klatt P, Werner ER, Schmidt K (1994) Molecular mechanisms of inhibition of porcine brain nitric oxide synthase by the antinociceptive drug 7-nitro-indazole. Neuropharmacology 33:12531259.

Mecocci P, MacGarvey U, Kaufman AE, Koontz D, Shoffner JM, Wallace DC, Beal MF (1993) Oxidative damage to mitochondrial DNA shows marked age-dependent increases in human brain. Ann Neurol 34:609-616.

Moncada C, Lekieffre D, Arvin B, Meldrum B (1992) Effect of NO synthase inhibition on NMDA- and ischaemia-induced hippocampal lesions. Neuroreport 3:530-532.

Moore PK, Wallace P, Gatten L, Hart SL, Babbedge RC (1993) Characterization of the novel nitric oxide synthase inhibitor 7-nitro indazole and related indazoles: antinociceptive and cardiovacular effects. Br J Pharmacol 110:219-224.

Nowicki JP, Duval D, Poignet H, Scatton B (1991) Nitric oxide mediates neuronal death after focal cerebral ischemia in the mouse. Eur J Pharmacol 204:339-340.

Park E-M, Shigenaga MK, Degan P, Korn TS, Kitzler JW, Wehr CM, Kolachana P, Ames BN (1992) Assay of excised oxidative DNA lesions: isolation of 8-oxoguanine and its nucleoside derivatives from biological fluids with a monoclonal antibody column. Proc Natl Acad Sci USA 89:3375-3379.

Pauwels PJ, Leysen JE (1992) Blockade of nitric oxide formation does not prevent glutamate-induced neurotoxicity in neuronal cultures from rat hippocampus. Neurosci Lett 143:27-30.

Regan RF, Renn KE, Panter SS (1993) NMDA neurotoxicity in murine cortical cell cultures is not attenuated by hemoglobin or inhibition of nitric oxide synthesis. Neurosci Lett 153:53-56.

Schulz JB, Henshaw DR, Siwek D, Jenkins BG, Ferrante RJ, Cipolloni PB, Kowall NW, Rosen BR, Bcal MF (1995a) Involvement of frec radicals in excitotoxicity in vivo. J Neurochem 64: in press.

Schulz JB, Matthews RT, Muqit MMK, Browne SE, Beal MF (1995b)
Inhibition of neuronal nitric oxide synthase by 7 -nitroindazole protects against MPTP induced neurotoxicity in mice. J Neurochem 64: 936-939.

Schweizer M, Richter C' (1994) Nitric oxide potently and reversibly deenergizes mitochondria at low oxygen tension. Biochem Biophys Res Commun 204:169-175.

Tymianski M, Charlton MP, Carlen PL, Tator CH (1993) Source specificity of early calcium neurotoxicity in cultured embryonic spinal neurons. J Neurosci 13:2085-2104.

van der Vliet A, O'Neill CA, Halliwell B, Cross CE, Kaur H (1994) Aromatic hydroxylation and nitration of phenylalanine and tyrosine by peroxynitrite. Evidence for hydroxyl radical production from peroxynitrite. FEBS Lett 339:89-92.

Vigé X, Carreau A, Scatton B, Nowicki JP (1993) Antagonism by $\mathrm{N}^{\mathrm{C}}$ nitro-L-arginine of L-glutamate-induced neurotoxicity in cultured neonatal rat cortical neurons. Prolonged application enhances neuroprotective effects. Neuroscience 55:893-901.

Vincent SR, Johansson O (1983) Striatal neuruns containing both sumatostatin- and avian pancreatic polypeptide (APP)-like immunoreactivities and $\mathrm{NADPH}$-diaphorase activity; a light and electron microscopic study. J Comp Neurol 217:264-270.

Wolff DJ, Gribin BJ (1994) The inhibition of the constitutive and inducible oxide synthase isoforms by indazole agents. Arch Biochem Biophys 311:300-306.

Wolff DJ, Lubeskie A, Umansky S (1994) The inhibition of the constitutive bovine endothelial nitric oxide synthase by imidazole and indazole agents. Arch Biochem Biophys 314:360-366.

Yoshida T, Limmroth V, Irikura K, Moskowitz MA (1994) The NOS inhibitor, 7-nitroindazole, decreases focal infarct volume but not the response to topical acetylcholine in pial vessels. J Cereb Blood Flow Metab 14:924-929.

Zhang J, Dawson VL, Dawson TM, Snyder SH (1994) Nitric oxide activation of poly(ADP-ribose) synthetase in neurotoxicity. Science 263:687-689.

Zinkand WC, Stumpo RJ, Thompson C, Patel J, Pullan LM (1993) Lack of involvement of nitric oxide in NMDA-induced neuronal cell death in cortical culture. Neuroreport 5:148-150. 